\title{
Influence of Anode Area and Electrode Gap on the Morphology of $\mathrm{TiO}_{2}$ Nanotubes Arrays
}

\author{
Min Wang, ${ }^{1,2}$ Li Jia, ${ }^{1}$ and Shuangmei Deng ${ }^{2}$ \\ ${ }^{1}$ Department of Power Engineering, School of Mechanical and Electronic Control Engineering, Beijing Jiaotong University, \\ Beijing 100044, China \\ ${ }^{2}$ Key Laboratory of Urban Stormwater System and Water Environment, Beijing University of Civil Engineering and Architecture, \\ Ministry of Education, Beijing 100044, China
}

Correspondence should be addressed to Min Wang; wangmin@bucea.edu.cn

Received 27 March 2013; Revised 30 April 2013; Accepted 5 May 2013

Academic Editor: Amir Kajbafvala

Copyright (C) 2013 Min Wang et al. This is an open access article distributed under the Creative Commons Attribution License, which permits unrestricted use, distribution, and reproduction in any medium, provided the original work is properly cited.

In order to fabricate the titanium dioxide $\left(\mathrm{TiO}_{2}\right)$ nanotubes arrays which were used in the photocatalytic degradation of total volatile organic compounds (TVOC) by anodization, the influence of the electrode gap and anode area on the morphology of the titanium dioxide $\left(\mathrm{TiO}_{2}\right)$ nanotubes was studied. Titanium dioxide $\left(\mathrm{TiO}_{2}\right)$ nanotube arrays were prepared by anodization with various electrode gaps and anode areas. Field emission scanning electron microscopy was used to investigate the morphology of the $\mathrm{TiO}_{2}$ nanotubes arrays. The results showed that the morphology of $\mathrm{TiO}_{2}$ nanotubes arrays was influenced by electrode gap and anode area. The appropriate anode area and electrode gap were $5 \mathrm{~cm} \times 2 \mathrm{~cm}$ and $20 \mathrm{~mm}$, respectively. Thus, $\mathrm{TiO}_{2}$ nanotube arrays with better morphology (with larger dimension and uniform $\mathrm{TiO}_{2}$ nanotubes) were successfully fabricated by anodic oxidation with $5 \mathrm{~cm} \times 2 \mathrm{~cm}$ anode area and $20 \mathrm{~mm}$ electrode gap at $30 \mathrm{~V}$.

\section{Introduction}

$\mathrm{TiO}_{2}$ nanotube arrays are extensively studied for water and air purification because of their nontoxicity, chemical stability, and superior photocatalytic activity [1-9]. $\mathrm{TiO}_{2}$ nanotube arrays can be fabricated by many different methods such as hydrothermal treatment [10-13], template-assistant deposition [14, 15], and electrochemical anodization [16-21]. The anodization method is a simple and effective technique for the rapid preparation of aligned $\mathrm{TiO}_{2}$ nanotubes due to the unnecessity of vacuum and high temperature [20, 2226]. Moreover, Using anodic oxidation, $\mathrm{TiO}_{2}$ is formed with a chemical bond between the oxide and $\mathrm{Ti}$ substrate; $\mathrm{TiO}_{2}$ nanotube arrays have a strong combination with Ti substrate, which provides convenience for $\mathrm{TiO}_{2}$ reusability $[27,28]$. In addition, the architecture of the nanotubes by the anodization method can be easily modified by manipulating the anodizing environments [29-31].

Owing to its wide band gap ( $3.2 \mathrm{eV}$ for anatase), anatase $\mathrm{TiO}_{2}$ can only be excited under ultraviolet irradiation.
However, this section occupies only less than $5 \%$ of the solar irradiance at the Earth's surface. For the sake of efficient use of sunlight, enlarging the absorption band border of $\mathrm{TiO}_{2}$ may be an appealing challenge for developing the future generation of photocatalysts. The improvement of photocatalytic efficiency by modifying $\mathrm{TiO}_{2}$ has been focused on for a long time $[32,33]$. Coupling $\mathrm{TiO}_{2}$ with a small band-gap semiconductor or doping with transition metal ions such as $\mathrm{V}, \mathrm{Cr}, \mathrm{Mn}, \mathrm{Fe}, \mathrm{Co}, \mathrm{Ni}$, or $\mathrm{Cu}$ extends the absorption spectrum range and improves the efficiency of photocatalyst [34-37]. Yang et al. [38] recently assembled $\mathrm{Cu}_{2} \mathrm{O}$ nanoparticles on the top surface of the $\mathrm{TiO}_{2}$ nanotube arrays (TNAs) by anodizing method. However, these $\mathrm{Cu}_{2} \mathrm{O}$ nanoparticles were supported mainly on the top surface of the TNAs, leading to insufficiently effective electron pathways between the $\mathrm{Cu}_{2} \mathrm{O}$ and $\mathrm{TiO}_{2}$. Therefore, in order to deposit these nanoparticles into the inner and external walls of the nanotubes uniformly, highly structured and orderly arranged $\mathrm{TiO}_{2}$ nanotube arrays with larger pore size must be prepared. 
TABLE 1: Electrochemical conditions and the morphologies of the samples.

\begin{tabular}{|c|c|c|c|c|c|}
\hline Exp. & Anode area $\left(\mathrm{cm}^{2}\right)$ & Electrode Gap (mm) & Applied voltage $(\mathrm{V})$ & Average diameter $(\mathrm{nm})$ & Length $(\mu \mathrm{m})$ \\
\hline 1 & $5 \times 0.5$ & \multirow{4}{*}{20} & & \multicolumn{2}{|c|}{ Without nanotube } \\
\hline 2 & $5 \times 1$ & & & $20 \pm 5$ (with crannies) & - \\
\hline 3 & $5 \times 2$ & & & $15 \pm 5$ & - \\
\hline 4 & $5 \times 4$ & & 10 & \multicolumn{2}{|c|}{ Without nanotube } \\
\hline 5 & & 5 & & \multicolumn{2}{|c|}{ Without nanotube } \\
\hline 6 & & 10 & & $15 \pm 5$ (with crannies) & - \\
\hline 7 & $5 \times 2$ & 40 & & \multicolumn{2}{|c|}{ Without nanotube } \\
\hline 8 & & \multirow{2}{*}{20} & 20 & $75 \pm 5$ & $1.0 \pm 0.2$ \\
\hline 9 & & & 30 & $180 \pm 20$ & $2 \pm 0.4$ \\
\hline
\end{tabular}

The morphology and the structure of nanotubes are affected strongly by the electrochemical conditions (particularly the anodization voltage) and the solution parameters (in particular the HF concentration, the, $\mathrm{pH}$ and the water content in the electrolyte) [39]. Many researchers [3, 9, $26,31,40,41]$ varied the parameters such as anodization potentials and anodization durations to fabricate the specific morphology of $\mathrm{TiO}_{2}$ nanotubes arrays (TNAs). Kim et al. [42] and Paulose et al. [43] demonstrated that the morphology of nanotubes is strongly influenced by the applied potential, and water content of electrolytes. Several reports [17, 41, 44-46] have shown that $\mathrm{F}^{-}$is crucial to the formation of nanotubular structures, and diluted $\mathrm{F}^{-}$electrolyte is preferred. To increase the nanotubular length, organic and viscous electrolytes have been experimented utilizing ethylene glycol or glycerol [4749]. A review of the literature related to $\mathrm{TiO}_{2}$ nanotube arrays reveals no published study on the effects of the anode area and electrode gap on the morphology and the structure of the resulting $\mathrm{TiO}_{2}$ nanotube arrays.

In this work, we report the effect of different anode areas and electrode gaps on the morphology of fabricated $\mathrm{TiO}_{2}$ nanotubes in ethylene glycol (EG) electrolytes containing ammonium fluoride $\left(\mathrm{NH}_{4} \mathrm{~F}\right)$ and $\mathrm{H}_{2} \mathrm{O}$. The microstructures of the samples are investigated by field emission scanning electron microscopy (FE-SEM).

\section{Experimental}

2.1. Materials. Titanium foils ( $0.2 \mathrm{~mm}$ thick, $99.95 \%$ purity) were mechanically polished by different abrasive papers (600\#, 1000\#, 1200\#, and 1800\#) then followed by sonicating acetone, ethanol, and deionized water for $30 \mathrm{~min}$. respectively. Then the titanium foils were dried at room temperature in air. All the other chemicals were of analytical grade and used as received without further purification.

2.2. Preparation of $\mathrm{TiO}_{2}$ Nanotube Arrays. A two-electrode polyethylene plastic cell $(V=300 \mathrm{~mL})$ was used to perform the anodization process. The pretreated $\mathrm{Ti}$ foil was used as an anode and Pt sheet as the cathode. Both electrodes were immersed in $200 \mathrm{~mL}$ organic electrolyte containing $0.4 \mathrm{wt} . \% \mathrm{NH}_{4} \mathrm{~F}, 5$ vol. $\% \mathrm{H}_{2} \mathrm{O}$, and 95 vol. $\%$ ethylene glycol (EG). All electrolytes were prepared from analytical grade and deionized water $(>18 \mathrm{M} \Omega \mathrm{cm})$. Ti foil was cut into $5 \mathrm{~cm} \times 0.5 \mathrm{~cm}, 5 \mathrm{~cm} \times 1 \mathrm{~cm}, 5 \mathrm{~cm} \times$ $2 \mathrm{~cm}$, and $5 \mathrm{~cm} \times 4 \mathrm{~cm}$, with $4 \mathrm{~cm} \times 0.5 \mathrm{~cm}, 4 \mathrm{~cm} \times 1 \mathrm{~cm}$, $4 \mathrm{~cm} \times 2 \mathrm{~cm}$, and $4 \mathrm{~cm} \times 4 \mathrm{~cm}$ areas exposed to the bulk electrolyte, respectively. The applied voltages were set to 10,20 , and $30 \mathrm{~V}$ by a DC power source (DH1718E-4), respectively. The electrochemical experiments were carried out at room temperature $\left(\sim 28^{\circ} \mathrm{C}\right)$, and the electrolyte was kept uniform with constant magnetic stirring, the stirring speed was kept constant at $\sim 180 \mathrm{rpm}$. The specimens were anodized for $1 \mathrm{~h}$. under different electrochemical conditions. The detailed electrochemical conditions are listed in Table 1. The anode area and electrode gap were changed for the systemic investigation of the formation of $\mathrm{TiO}_{2}$ nanotubes. The as-anodized samples were rinsed with deionized water and dried in air.

2.3. Characterization Technique. The surface morphologies of obtained samples were observed using field emission scanning electron microscope (FE-SEM, Hitachi S-4800). Direct SEM cross-sectional observations were carried out on flat and cracked samples.

\section{Results and Discussion}

3.1. Influence of Anode Area on the Top Morphology of $\mathrm{TiO}_{2}$ Nanotube. The $\mathrm{TiO}_{2}$ nanotubes formation mechanism includes the following processes [50-52].

(i) Formation of oxide layer at the surface of the metal takes place due to interaction of the metal with $\mathrm{O}^{2-}$ or $\mathrm{OH}^{-}$ions. After the development of an initial oxide layer, these ions move through the oxide layer towards the metal/oxide interface where they react with the $\mathrm{Ti}$ metal. The reaction can be represented as follows:

$$
\begin{gathered}
\mathrm{Ti}-4 \mathrm{e}^{-} \longrightarrow \mathrm{Ti}^{4+} \\
\mathrm{O}_{2}+4 \mathrm{e}^{-} \longrightarrow 2 \mathrm{O}^{2-} \\
\mathrm{Ti}^{4+}+2 \mathrm{O}^{2-} \longrightarrow \mathrm{TiO}_{2} \\
\mathrm{Ti}^{4+}+2 \mathrm{OH}^{-} \longrightarrow \mathrm{TiO}_{2}+2 \mathrm{H}^{+} .
\end{gathered}
$$


(ii) Field-assisted dissolution of Titanium oxideMetal ion $\left(\mathrm{Ti}^{4+}\right)$ transfer from the Ti metal at the metal/oxide interface by ejection under application of an electric field and migrate towards the oxide/electrolyte interface. $\mathrm{Ti}^{4+}$ cations dissolve into the electrolyte, and the free $\mathrm{O}^{2-}$ anions transfer towards the metal/oxide interface to interact with the Ti metal. The fieldassisted dissolution of titanium oxide is represented by the following reaction:

$$
\mathrm{TiO}_{2} \longrightarrow \mathrm{Ti}^{4+}+2 \mathrm{O}^{2-} \text {. }
$$

(iii) Chemical dissolution of the Ti metal or oxide also occurs due to the acidic and fluorine contained electrolyte, which then causes more etching at the porebottom than at the opening and the walls. Therefore, in the early stages of the anodization process, small pits are formed. The formation of these small pits is represented by the following reaction:

$$
\mathrm{TiO}_{2}+6 \mathrm{~F}^{-}+4 \mathrm{H}^{+} \longrightarrow \mathrm{TiF}_{6}{ }^{2-}+2 \mathrm{H}_{2} \mathrm{O} \text {. }
$$

Therefore, the growth and propagation of the pores occur by inward movement at the oxide/metal interface, which is determined by the amount of fluorine on the anode surface and the degree of electric field. Figure 1 shows the surface images of the samples during anodization of titanium at $10 \mathrm{~V}$ in $0.4 w t \% \mathrm{NH}_{4} \mathrm{~F}+5 \mathrm{wt} \% \mathrm{H}_{2} \mathrm{O}$ EG solution with different anode areas. With $5 \mathrm{~cm} \times 0.5 \mathrm{~cm}$ anode area, the top of the sample is covered by much debris, and no nanotube is found on the surface (Figure 1(a)). We suppose that with a smaller anode area, the current density and the field effect are too high. Thus, the higher electric field would polarise and weaken $\mathrm{Ti}-\mathrm{O}$ bond resulting in dissolution of oxide rapidly before small pores formation. In addition, the rate of the chemical dissolution on the anodes of the smaller area is higher due to the more fluoride ions per anode unit area, resulting in dissolution of oxide rapidly before small pores formation. With $5 \mathrm{~cm} \times 1 \mathrm{~cm}$ anode area, the surface morphologies consist of ring-like structures whose the openings are around $20 \mathrm{~nm}$ in diameter, and numerous crannies are observed on the surface (Figure 1(b)). The samples prepared with $5 \mathrm{~cm} \times 2 \mathrm{~cm}$ anode at $10 \mathrm{~V}$ (Figure $1(\mathrm{c})$ ) consist of a ringlike structure with diameter of less than $20 \mathrm{~nm}$, no debris and crannies are found on the surface. At the initial stage of anodisation, the rate of the field-assisted dissolution on the anodes of different area is equal due to the same applied voltage, while the rate of the chemical dissolution on the anodes of the larger area is lower due to the less fluoride ions per anode unit area, which results in the oxide thickness reduction being slower on the larger area anode [53]. As the anodisation proceeds and oxide thickens, the rate of the fieldassisted dissolution on the larger area anode decreases faster than that of the smaller area anode [53]. So, we can speculate that with the increase of the anode area, the electric fieldassisted dissolution of the oxide is weakened, the chemical dissolution dominates electric field-assisted dissolution, and the growth and propagation of the tubes occur by inward movement at the oxide/metal interface, thereby forming nanotubes. At the meantime, when the current density is beyond certain value, electric field-assisted dissolution is believed to occur too rapidly, polarizing and weakening the $\mathrm{Ti}-\mathrm{O}$ band not only at the bottom part of the nanotubes but also along the longitudinal direction of the nanotubes as well; hence more crannies are produced.

As shown in Figure 1(d) for the $5 \mathrm{~cm} \times 4 \mathrm{~cm}$ anode area, the $\mathrm{TiO}_{2}$ layer is more compact and only some small pits disperse sparsely, no nanotubes are observed; however, $\mathrm{Ti}$ is partly etched. Under this condition, the anode area is too large, resulting in the fact that the amount of fluorine ions per square centimeter at the anode surface is less, the rate of the reaction (3) decreases rapidly [54]; thus, the $\mathrm{TiO}_{2}$ layer is thicker, which results in less electric field dissolution [53]. Therefore, the formation of nanotubes by anodization fails. The appreciate anode area for $\mathrm{TiO}_{2}$ nanotube formation is, therefore, around $5 \mathrm{~cm} \times 2 \mathrm{~cm}$ in the $200 \mathrm{~mL} 0.4 \mathrm{wt} \% \mathrm{NH}_{4} \mathrm{~F}+$ $5 \mathrm{wt} \% \mathrm{H}_{2} \mathrm{O}$ EG solution.

\subsection{Influence of Electrode Gap on the Top Morphology of} $\mathrm{TiO}_{2}$ Nanotubes. Figure 2 shows the surface images of $\mathrm{TiO}_{2}$ nanotubes prepared with different electrode gaps. When the electrode gap is $5 \mathrm{~mm}$, the morphology which is covered by the thicker oxide layer with severely localized shedding is observed (Figure 2(a)). Because the smaller electrode gap is, the solution resistance between electrodes is lower, the rate $\mathrm{O}^{2-}$ or $\mathrm{OH}^{-}$ions to the anode increase; therefore, the rate of the reactions (1a), (1b), (1c), and (1d) is higher; that is, the formation of $\mathrm{TiO}_{2}$ layer is faster. On the other hand, the $\mathrm{F}^{-}$ ions quickly reach the anode and the $\mathrm{Ti}^{4+}$ ions quickly leave the anode, resulting in the fact that the chemical dissolution and electric field dissolution of the $\mathrm{TiO}_{2}$ layer rapidly occur. So the oxide layer on the sample surface is etched severely. Samples anodized at a $10 \mathrm{~mm}$ electrode gap consist of a ringlike structure with a diameter of $<30 \mathrm{~nm}$ and some crannies (Figure 2(b)). With increased electrode gap, the rate of the $\mathrm{TiO}_{2}$ layer formation and dissolution is slowed down. Under this condition, the reaction (3) on the bottom of the pits continues, so lots of ring-like structures occur, but the higher the electric field intensity due to the smaller electrode gap results in stronger field-assisted dissolution of $\mathrm{TiO}_{2}$ on the sample surface. Therefore, there are lots of $\mathrm{TiO}_{2}$ crannies on the sample surface. Increasing the electrode gap to $20 \mathrm{~mm}$, Figure 1(c) shows the ring-like structure without any cranny on the sample surface. The inward movement rate of the oxide/metal interface is approximately equal to the rate of the reaction (3). So, a discrete, hollow-like cylindrical structure was formed which developed into the nanotubular structure with diameters of $<20 \mathrm{~nm}$. At the meantime, with decreased electric field intensity, the electric field dissolution of the oxide occurs much slower, thus without forming crannies on the surface. At $40 \mathrm{~mm}$ electrode gap (Figure 2(c)), the $\mathrm{TiO}_{2}$ layer is more compact and many pit structures are observed. Under this condition, the higher electrical resistance due to the larger electrode gap results in that the inward movement rate of the $\mathrm{F}^{-}$ions is decreased, only small pits are formed without any nanotubes on the surface. And the weaker 


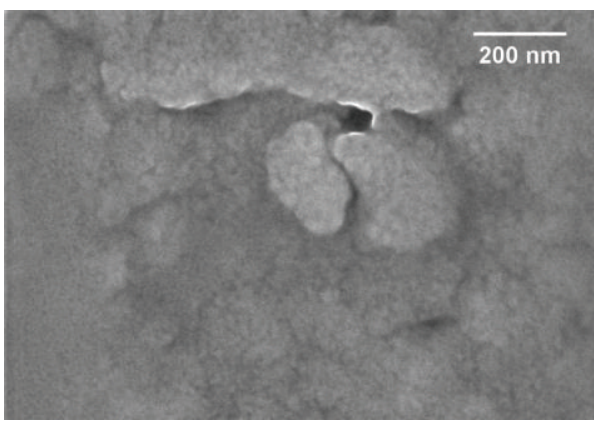

(a)

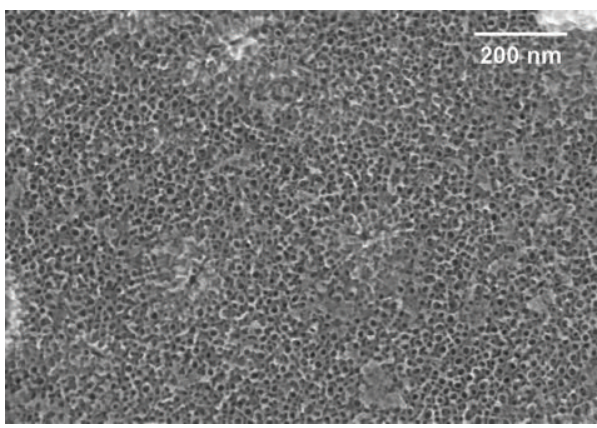

(c)

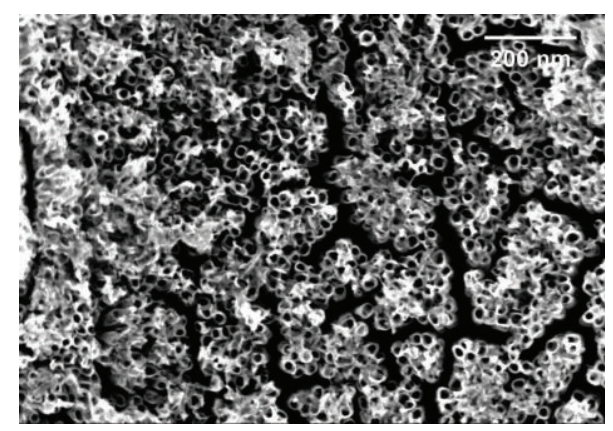

(b)

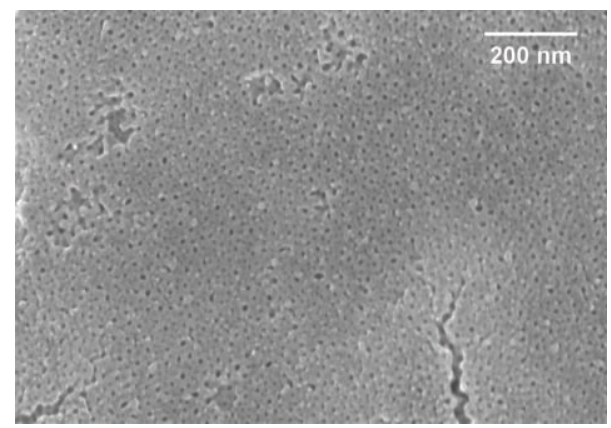

(d)

Figure 1: FE-SEM images of the surface morphology of $\mathrm{TiO}_{2}$ nanotube arrays formed at $10 \mathrm{~V}$ in ethylene glycol containing $0.4 \mathrm{wt} \% \mathrm{NH}_{4} \mathrm{~F}$ and $5 \mathrm{wt} \% \mathrm{H}_{2} \mathrm{O}$ electrolyte for $1 \mathrm{~h}$. with different anode areas: (a) $5 \mathrm{~cm} \times 0.5 \mathrm{~cm}$, (b) $5 \mathrm{~cm} \times 1 \mathrm{~cm}$, (c) $5 \mathrm{~cm} \times 2 \mathrm{~cm}$, and (d) $5 \mathrm{~cm} \times 4 \mathrm{~cm}$.

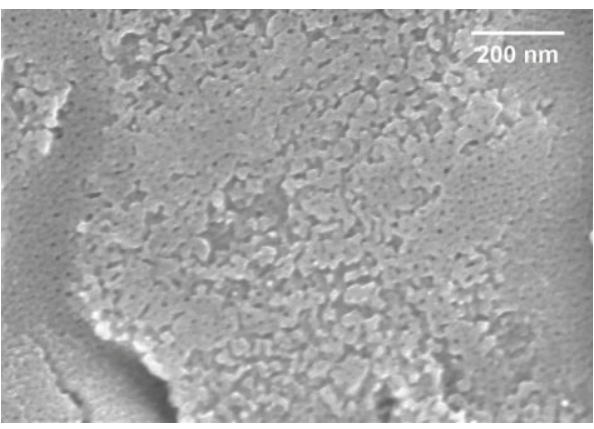

(a)

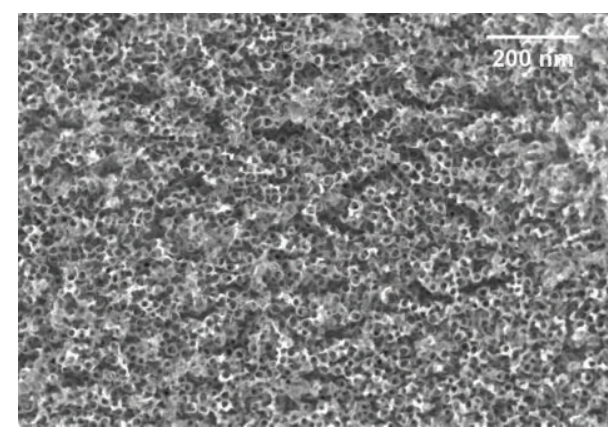

(b)

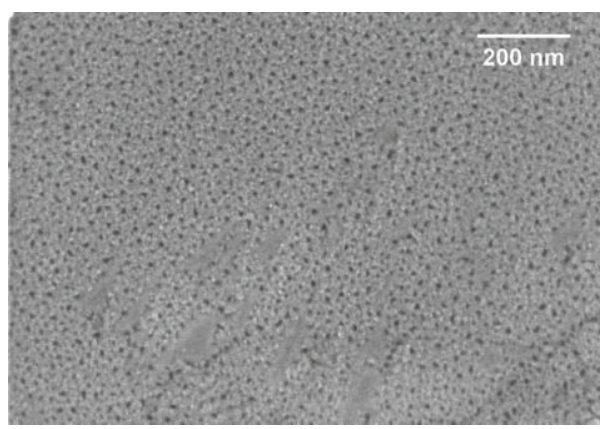

(c)

FIGURE 2: FE-SEM images of the surface morphology of $\mathrm{TiO}_{2}$ nanotube arrays formed at $10 \mathrm{~V}$ in ethylene glycol containing $0.4 \mathrm{wt} \% \mathrm{NH}_{4} \mathrm{~F}$ and $5 \mathrm{wt} \% \mathrm{H}_{2} \mathrm{O}$ electrolyte for $1 \mathrm{~h}$. with different electrode gaps: (a) $5 \mathrm{~mm}$, (b) $10 \mathrm{~mm}$, and (c) $40 \mathrm{~mm}$. 


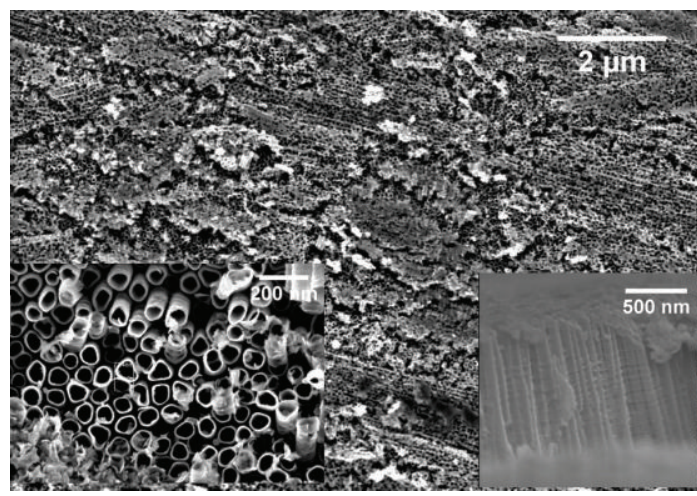

(a)

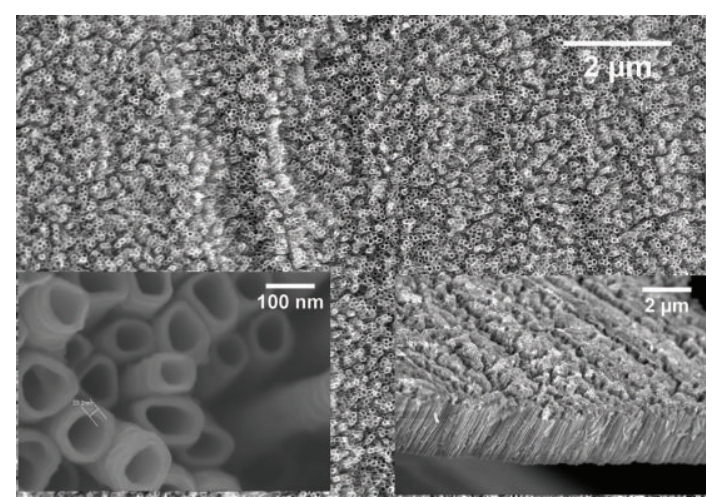

(b)

Figure 3: FE-SEM images of the surface morphology of $\mathrm{TiO}_{2}$ nanotube arrays formed in ethylene glycol containing $0.4 \mathrm{wt} \% \mathrm{NH}_{4} \mathrm{~F}$ and $5 \mathrm{wt} \%$ $\mathrm{H}_{2} \mathrm{O}$ electrolyte at different voltages for $1 \mathrm{~h}$. (a) 20 and (b) $30 \mathrm{~V}$.

electric field dissolution due to the smaller electric field intensity does not generate crannies on the sample surface.

According to the aforementioned experiments, it is inferred that samples anodized with $20 \mathrm{~mm}$ electrode gap will suffer from appreciate chemical and electric field dissolution forming nanotube structure with smaller diameter with the ratio of electrode area to electrolyte volume being $0.05 \mathrm{~cm}^{-1}$. Under this condition, anodisation experiments at higher voltages $(20 \mathrm{~V}, 30 \mathrm{~V})$ were carried out to seek the possibility of increasing the length and diameter of the nanotubes further. Surface morphologies of $\mathrm{TiO}_{2}$ formed at $20 \mathrm{~V}$ and $30 \mathrm{~V}$ are shown in Figures 3(a) and 3(b) when the samples are anodized for $1 \mathrm{~h}$. The surface morphologies consist of ringlike structures related to the opening of nanotubes. The insets are the cross-sectional images and higher magnifications of the same sample. The length of the nanotubes increases from $1 \mu \mathrm{m}$ to $2.4 \mu \mathrm{m}$, and the diameter of the nanotubes increases from $70 \mathrm{~nm}$ to $200 \mathrm{~nm}$ for samples anodized at 20 and $30 \mathrm{~V}$, respectively. As reported by Lockman et al. [53], pore growth occurs at a higher voltage, thereby increasing the length and diameter of the nanotubes, but the nanotubes structure starts to be deteriorated at $25 \mathrm{~V}$ and is completely lost at $30 \mathrm{~V}$. Therefore, the joint effect of electrolysis conditions such as voltage, electrode area, electrode gap, composition of the electrolytic solution, and temperature on the nanotubes morphologies needs to be studied further.

\section{Conclusion}

In conclusion, it is demonstrated that the surface morphology of $\mathrm{TiO}_{2}$ nanotube arrays which were used in the photocatalytic degradation of total volatile organic compounds (TVOC) can be modified by anodization of Ti foils in EG solution consisting of $0.4 \% \mathrm{NH}_{4} \mathrm{~F}$ and $5 \%$ wt $\mathrm{H}_{2} \mathrm{O}$ using the appropriate anode area and electrode gap. The effect of anode area and electrode gap on surface morphology of $\mathrm{TiO}_{2}$ nanotube arrays was investigated and the results of SEM show that the highly ordered $\mathrm{TiO}_{2}$ nanotube arrays cannot be formed with inappropriate anode area and electrode gap. Moreover, a detailed theoretical interpretation of the influence of anode area and electrode gap on the morphology of TNAs was introduced. With appropriate anode area $5 \mathrm{~cm}$ $\times 2 \mathrm{~cm}$ and electrode gap $20 \mathrm{~mm}$, larger-dimension, and uniform $\mathrm{TiO}_{2}$ nanotube arrays were successfully formed after $1 \mathrm{~h}$. of anodization of pure titanium foil in a two-electrode bath with $200 \mathrm{~mL}$ electrolyte solution at $30 \mathrm{~V}$.

\section{Acknowledgment}

The work has been supported by Science and Technology Planning Project of the Ministry of Science and Technology of China (no. 2012BAB12B02).

\section{References}

[1] K. Nakata, T. Ochiai, T. Murakami, and A. Fujishima, "Photoenergy conversion with $\mathrm{TiO}_{2}$ photocatalysis: new materials and recent applications," Electrochimica Acta, vol. 84, pp. 103111, 2012.

[2] A. Zhang, M. Zhou, L. Han, and Q. Zhou, "The combination of rotating disk photocatalytic reactor and $\mathrm{TiO}_{2}$ nanotube arrays for environmental pollutants removal," Journal of Hazardous Materials, vol. 186, no. 2-3, pp. 1374-1383, 2011.

[3] J. Bai, Y. Liu, J. Li, B. Zhou, Q. Zheng, and W. Cai, "A novel thinlayer photoelectrocatalytic (PEC) reactor with double-faced titania nanotube arrays electrode for effective degradation of tetracycline," Applied Catalysis B, vol. 98, no. 3-4, pp. 154-160, 2010.

[4] H. Liu, G. Liu, J. Fan et al., "Photoelectrocatalytic degradation of $4,4^{\prime}$-dibromobiphenyl in aqueous solution on $\mathrm{TiO}_{2}$ and doped $\mathrm{TiO}_{2}$ nanotube arrays," Chemosphere, vol. 82, no. 1, pp. 43-47, 2011.

[5] Y. Muramatsu, Q. Jin, M. Fujishima, and H. Tada, "Visible-lightactivation of $\mathrm{TiO}_{2}$ nanotube array by the molecular iron oxide surface modification," Applied Catalysis B, vol. 119-120, pp. 7480, 2012.

[6] F. Jiang, S. Zheng, L. An, and H. Chen, "Effect of calcination temperature on the adsorption and photocatalytic activity of hydrothermally synthesized $\mathrm{TiO}_{2}$ nanotubes," Applied Surface Science, vol. 258, no. 18, pp. 7188-7194, 2012. 
[7] H. Li, L. Cao, W. Liu, G. Su, and B. Dong, "Synthesis and investigation of $\mathrm{TiO}_{2}$ nanotube arrays prepared by anodization and their photocatalytic activity," Ceramics International, vol. 38, no. 7, pp. 5791-5797, 2012.

[8] J. M. Macak, M. Zlamal, J. Krysa, and P. Schmuki, "Selforganized $\mathrm{TiO}_{2}$ nanotube layers as highly efficient photocatalysts," Small, vol. 3, no. 2, pp. 300-304, 2007.

[9] Y. Lai, H. Zhuang, L. Sun, Z. Chen, and C. Lin, "Self-organized $\mathrm{TiO}_{2}$ nanotubes in mixed organic-inorganic electrolytes and their photoelectrochemical performance," Electrochimica Acta, vol. 54, no. 26, pp. 6536-6542, 2009.

[10] T. Kasuga, M. Hiramatsu, A. Hoson, T. Sekino, and K. Niihara, "Titania nanotubes prepared by chemical processing," Advanced Materials, vol. 11, no. 15, pp. 1307-1311, 1999.

[11] Q. Chen, W. Zhou, G. H. Du, and L. M. Peng, "Trititanate nanotubes made via a single alkali treatment," Advanced Materials, vol. 14, no. 17, pp. 1208-1211, 2002.

[12] C. C. Tsai and H. Teng, "Regulation of the physical characteristics of titania nanotube aggregates synthesized from hydrothermal treatment," Chemistry of Materials, vol. 16, no. 22, pp. 4352-4358, 2004.

[13] J. N. Nian and H. Teng, "Hydrothermal synthesis of singlecrystalline anatase $\mathrm{TiO}_{2}$ nanorods with nanotubes as the precursor," Journal of Physical Chemistry B, vol. 110, no. 9, pp. 41934198, 2006.

[14] P. Hoyer, "Formation of a titanium dioxide nanotube array," Langmuir, vol. 12, no. 6, pp. 1411-1413, 1996.

[15] J. H. Lee, I. C. Leu, M. C. Hsu, Y. W. Chung, and M. H. Hon, "Fabrication of aligned $\mathrm{TiO}_{2}$ one-dimensional nanostructured arrays using a one-step templating solution approach," Journal of Physical Chemistry B, vol. 109, no. 27, pp. 13056-13059, 2005.

[16] V. Zwilling, E. Darque-Ceretti, A. Boutry-Forveille, D. David, M. Y. Perrin, and M. Aucouturier, "Structure and physicochemistry of anodic oxide films on titanium and TA6V alloy," Surface and Interface Analysis, vol. 27, no. 7, pp. 629-637, 1999.

[17] D. Gong, C. A. Grimes, O. K. Varghese et al., "Titanium oxide nanotube arrays prepared by anodic oxidation," Journal of Materials Research, vol. 16, no. 12, pp. 3331-3334, 2001.

[18] O. K. Varghese, D. Gong, M. Paulose, C. A. Grimes, and E. C. Dickey, "Crystallization and high-temperature structural stability of titanium oxide nanotube arrays," Journal of Materials Research, vol. 18, no. 1, pp. 156-165, 2003.

[19] O. K. Varghese, M. Paulose, K. Shankar, G. K. Mor, and C. A. Grimes, "Water-photolysis properties of micron-length highlyordered titania nanotube-arrays," Journal of Nanoscience and Nanotechnology, vol. 5, no. 7, pp. 1158-1165, 2005.

[20] H. Omidvar, S. Goodarzi, A. Seif, and A. R. Azadmehr, "Influence of anodization parameters on the morphology of $\mathrm{TiO}_{2}$ nanotube arrays," Superlattices and Microstructures, vol. 50, no. 1, pp. 26-39, 2011.

[21] S. Palmas, A. Da Pozzo, M. Mascia et al., "Effect of the preparation conditions on the performance of $\mathrm{TiO}_{2}$ nanotube arrays obtained by electrochemical oxidation," International Journal of Hydrogen Energy, vol. 36, no. 15, pp. 8894-8901, 2011.

[22] N. Kılınç, E. Şennik, and Z. Z. Öztürk, "Fabrication of $\mathrm{TiO}_{2}$ nanotubes by anodization of Ti thin films for VOC sensing," Thin Solid Films, vol. 520, no. 3, pp. 953-958, 2011.

[23] Y. Liu, D. Wang, L. Cao, and S. Chen, "Structural engineering of highly ordered $\mathrm{TiO}_{2}$ nanotube array by periodic anodization of titanium," Electrochemistry Communications, vol. 23, pp. 68-71, 2012.

[24] M. Okada, K. Tajima, Y. Yamada, and K. Yoshimura, "Selforganized formation of short $\mathrm{TiO}_{2}$ nanotube arrays by complete anodization of Ti thin films," Physics Procedia, vol. 32, pp. 714$718,2012$.

[25] J. Wang and Z. Lin, "Freestanding $\mathrm{TiO}_{2}$ nanotube arrays with ultrahigh aspect ratio via electrochemical anodization," Chemistry of Materials, vol. 20, no. 4, pp. 1257-1261, 2008.

[26] R. P. Antony, T. Mathews, A. Dasgupta, S. Dash, A. K. Tyagi, and B. Raj, "Rapid breakdown anodization technique for the synthesis of high aspect ratio and high surface area anatase $\mathrm{TiO}_{2}$ nanotube powders," Journal of Solid State Chemistry, vol. 184, no. 3, pp. 624-632, 2011.

[27] L. Li, Z. Zhou, J. Lei, J. He, S. Zhang, and F. Pan, "Highly ordered anodic $\mathrm{TiO}_{2}$ nanotube arrays and their stabilities as photo(electro)catalysts," Applied Surface Science, vol. 258, no. 8, pp. 3647-3651, 2012.

[28] G. A. Crawford, N. Chawla, K. Das, S. Bose, and A. Bandyopadhyay, "Microstructure and deformation behavior of biocompatible $\mathrm{TiO}_{2}$ nanotubes on titanium substrate," Acta Biomaterialia, vol. 3, no. 3, pp. 359-367, 2007.

[29] H. H. Ou and S. L. Lo, "Review of titania nanotubes synthesized via the hydrothermal treatment: fabrication, modification, and application," Separation and Purification Technology, vol. 58, no. 1, pp. 179-191, 2007.

[30] Y. Yu, J. C. Yu, C. Y. Chan et al., "Enhancement of adsorption and photocatalytic activity of $\mathrm{TiO}_{2}$ by using carbon nanotubes for the treatment of azo dye," Applied Catalysis B, vol. 61, no. 1-2, pp. 1-11, 2005.

[31] K. C. Sun, Y. C. Chen, M. Y. Kuo et al., "Synthesis and characterization of highly ordered $\mathrm{TiO}_{2}$ nanotube arrays for hydrogen generation via water splitting," Materials Chemistry and Physics, vol. 129, no. 1-2, pp. 35-39, 2011.

[32] L. Xiong, F. Yang, L. Yan et al., "Bifunctional photocatalysis of $\mathrm{TiO}_{2} / \mathrm{Cu}_{2} \mathrm{O}$ composite under visible light: $\mathrm{Ti}^{3+}$ in organic pollutant degradation and water splitting," Journal of Physics and Chemistry of Solids, vol. 72, no. 9, pp. 1104-1109, 2011.

[33] S. Zhang, S. Zhang, F. Peng, H. Zhang, H. Liu, and H. Zhao, "Electrodeposition of polyhedral $\mathrm{Cu}_{2} \mathrm{O}$ on $\mathrm{TiO}_{2}$ nanotube arrays for enhancing visible light photocatalytic performance," Electrochemistry Communications, vol. 13, no. 8, pp. 861-864, 2011.

[34] L. Zang, W. Macyk, C. Lange et al., "Visible-light detoxification and charge generation by transition metal chloride modified titania," Chemistry, vol. 6, no. 2, pp. 379-384, 2000.

[35] F. Bosc, D. Edwards, N. Keller, V. Keller, and A. Ayral, "Mesoporous $\mathrm{TiO}_{2}$-based photocatalysts for UV and visible light gasphase toluene degradation," Thin Solid Films, vol. 495, no. 1-2, pp. 272-279, 2006.

[36] C. Han, Z. Li, and J. Shen, "Photocatalytic degradation of dodecyl-benzenesulfonate over $\mathrm{TiO}_{2}-\mathrm{Cu}_{2} \mathrm{O}$ under visible irradiation," Journal of Hazardous Materials, vol. 168, no. 1, pp. 215219, 2009.

[37] H. Liu, H. K. Shon, X. Sun, S. Vigneswaran, and H. Nan, "Preparation and characterization of visible light responsive $\mathrm{Fe}_{2} \mathrm{O}_{3}-\mathrm{TiO}_{2}$ composites," Applied Surface Science, vol. 257, no. 13, pp. 5813-5819, 2011.

[38] L. Yang, S. Luo, Y. Li, Y. Xiao, Q. Kang, and Q. Cai, "High efficient photocatalytic degradation of p-nitrophenol on a 
unique $\mathrm{Cu}_{2} \mathrm{O} / \mathrm{TiO}_{2}$ p-n heterojunction network catalyst," Environmental Science and Technology, vol. 44, no. 19, pp. 7641-7646, 2010.

[39] J. M. Macak, H. Tsuchiya, A. Ghicov et al., “ $\mathrm{TiO}_{2}$ nanotubes: self-organized electrochemical formation, properties and applications," Current Opinion in Solid State and Materials Science, vol. 11, no. 1-2, pp. 3-18, 2007.

[40] R. Narayanan, T. Y. Kwon, and K. H. Kim, “ $\mathrm{TiO}_{2}$ nanotubes from stirred glycerol/ $\mathrm{NH}_{4} \mathrm{~F}$ electrolyte: roughness, wetting behavior and adhesion for implant applications," Materials Chemistry and Physics, vol. 117, no. 2-3, pp. 460-464, 2009.

[41] H. E. Prakasam, K. Shankar, M. Paulose, O. K. Varghese, and C. A. Grimes, "A new benchmark for $\mathrm{TiO}_{2}$ nanotube array growth by anodization," Journal of Physical Chemistry C, vol. 111, no. 20, pp. 7235-7241, 2007.

[42] S. E. Kim, J. H. Lim, S. C. Lee, S. C. Nam, H. G. Kang, and J. Choi, "Anodically nanostructured titanium oxides for implant applications," Electrochimica Acta, vol. 53, no. 14, pp. 4846-4851, 2008.

[43] M. Paulose, K. Shankar, S. Yoriya et al., "Anodic growth of highly ordered $\mathrm{TiO}_{2}$ nanotube arrays to $134 \mu \mathrm{m}$ in length," The Journal of Physical Chemistry B, vol. 110, no. 33, pp. 16179-16184, 2006.

[44] B. G. Lee, J. W. Choi, S. E. Lee, Y. S. Jeong, H. J. Oh, and C. S. Chi, "Formation behavior of anodic $\mathrm{TiO}_{2}$ nanotubes in fluoride containing electrolytes," Transactions of Nonferrous Metals Society of China (English Edition), vol. 19, no. 4, pp. 842845, 2009.

[45] W. Y. Choi, J. Chung, C. H. Cho, and J. O. Kim, "Fabrication and photocatalytic activity of a novel nanostructured $\mathrm{TiO}_{2}$ metal membrane," Desalination, vol. 279, no. 1-3, pp. 359-366, 2011.

[46] T. Ruff, R. Hahn, and P. Schmuki, "From anodic $\mathrm{TiO}_{2}$ nanotubes to hexagonally ordered $\mathrm{TiO}_{2}$ nanocolumns," Applied Surface Science, vol. 257, no. 19, pp. 8177-8181, 2011.

[47] X. Zeng, Y. X. Gan, E. Clark, and L. Su, "Amphiphilic and photocatalytic behaviors of $\mathrm{TiO}_{2}$ nanotube arrays on $\mathrm{Ti}$ prepared via electrochemical oxidation," Journal of Alloys and Compounds, vol. 509, no. 24, pp. L221-L227, 2011.

[48] K. Srimuangmak and S. Niyomwas, "Effects of voltage and addition of water on photocatalytic activity of $\mathrm{TiO}_{2}$ nanotubes prepared by anodization method," Energy Procedia, vol. 9, pp. 435-439, 2011.

[49] K. Shankar, G. K. Mor, A. Fitzgerald, and C. A. Grimes, "Cation effect on the electrochemical formation of very high aspect ratio $\mathrm{TiO}_{2}$ nanotube arrays in formamide-water mixtures," Journal of Physical Chemistry C, vol. 111, no. 1, pp. 21-26, 2007.

[50] A. El Ruby Mohamed and S. Rohani, "Modified $\mathrm{TiO}_{2}$ nanotube arrays (TNTAs): progressive strategies towards visible light responsive photoanode, a review," Energy and Environmental Science, vol. 4, no. 4, pp. 1065-1086, 2011.

[51] L. Sun, J. Li, C. L. Wang, S. F. Li, H. B. Chen, and C. J. Lin, "An electrochemical strategy of doping $\mathrm{Fe}^{3+}$ into $\mathrm{TiO}_{2}$ nanotube array films for enhancement in photocatalytic activity, Solar Energy Materials and Solar Cells, vol. 93, no. 10, pp. 1875-1880, 2009.

[52] J. Mo, Y. Zhang, Q. Xu, J. J. Lamson, and R. Zhao, "Photocatalytic purification of volatile organic compounds in indoor air: a literature review," Atmospheric Environment, vol. 43, no. 14, pp. 2229-2246, 2009.

[53] Z. Lockman, S. Sreekantan, S. Ismail, L. Schmidt-Mende, and J. L. MacManus-Driscoll, "Influence of anodisation voltage on the dimension of titania nanotubes," Journal of Alloys and Compounds, vol. 503, no. 2, pp. 359-364, 2010.

[54] H. J. Oh, I. K. Kim, K. W. Jang, J. H. Lee, S. Lee, and C. S. Chi, "Influence of electrolyte and anodic potentials on morphology of titania nanotubes," Metals and Materials International, vol. 18, no. 4, pp. 673-677, 2012. 

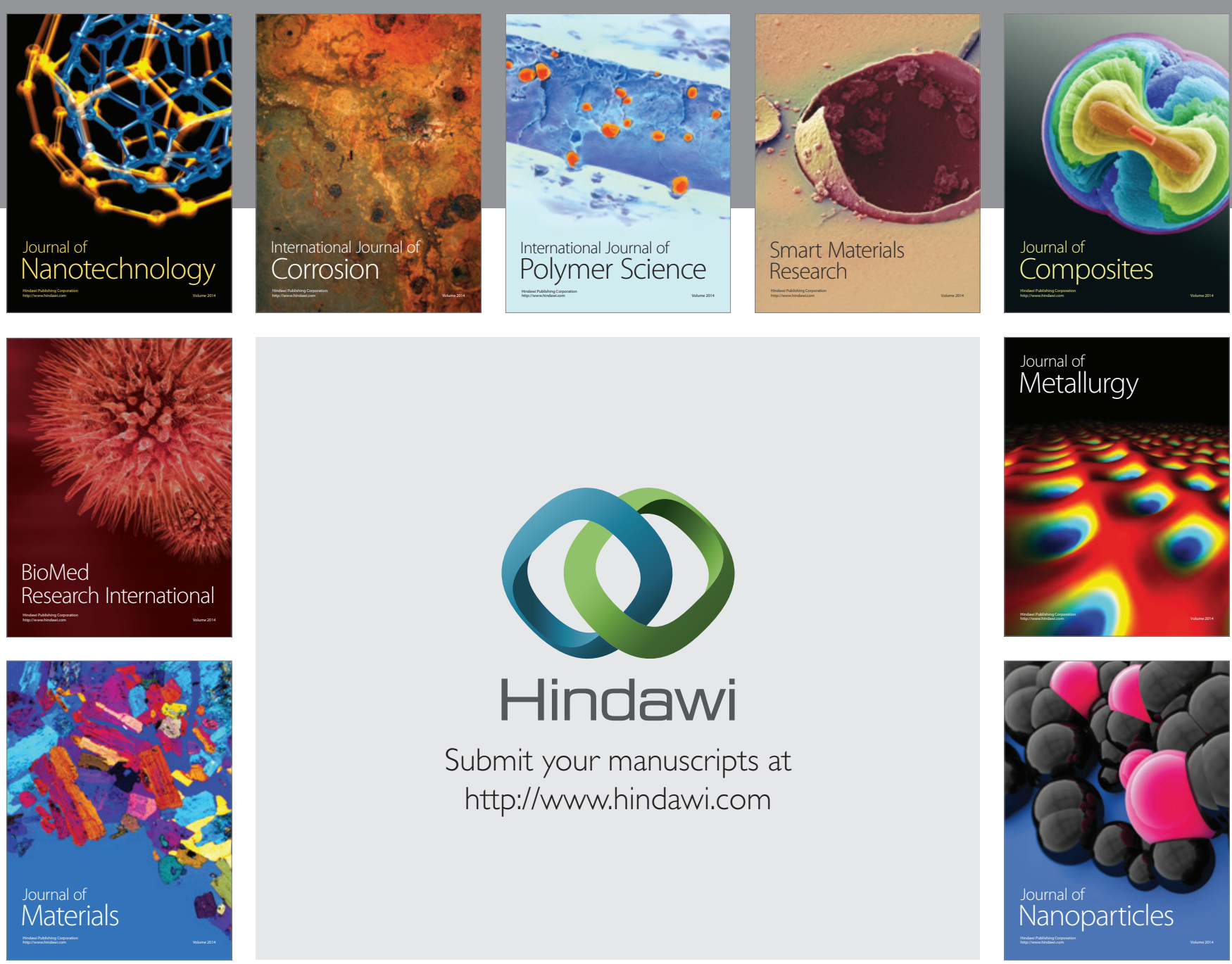

Submit your manuscripts at http://www.hindawi.com
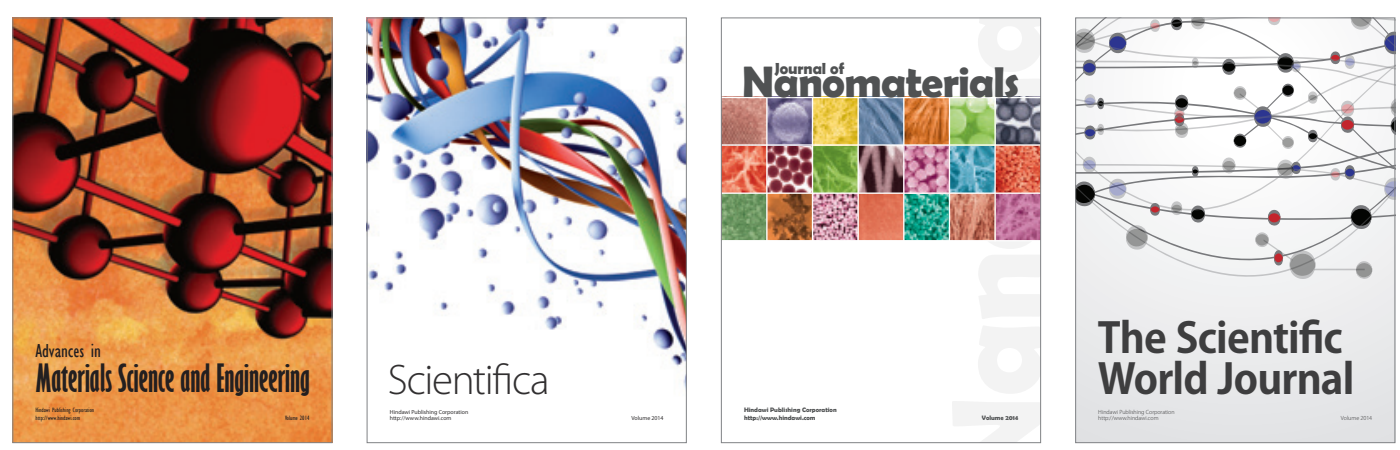

\section{The Scientific World Journal}
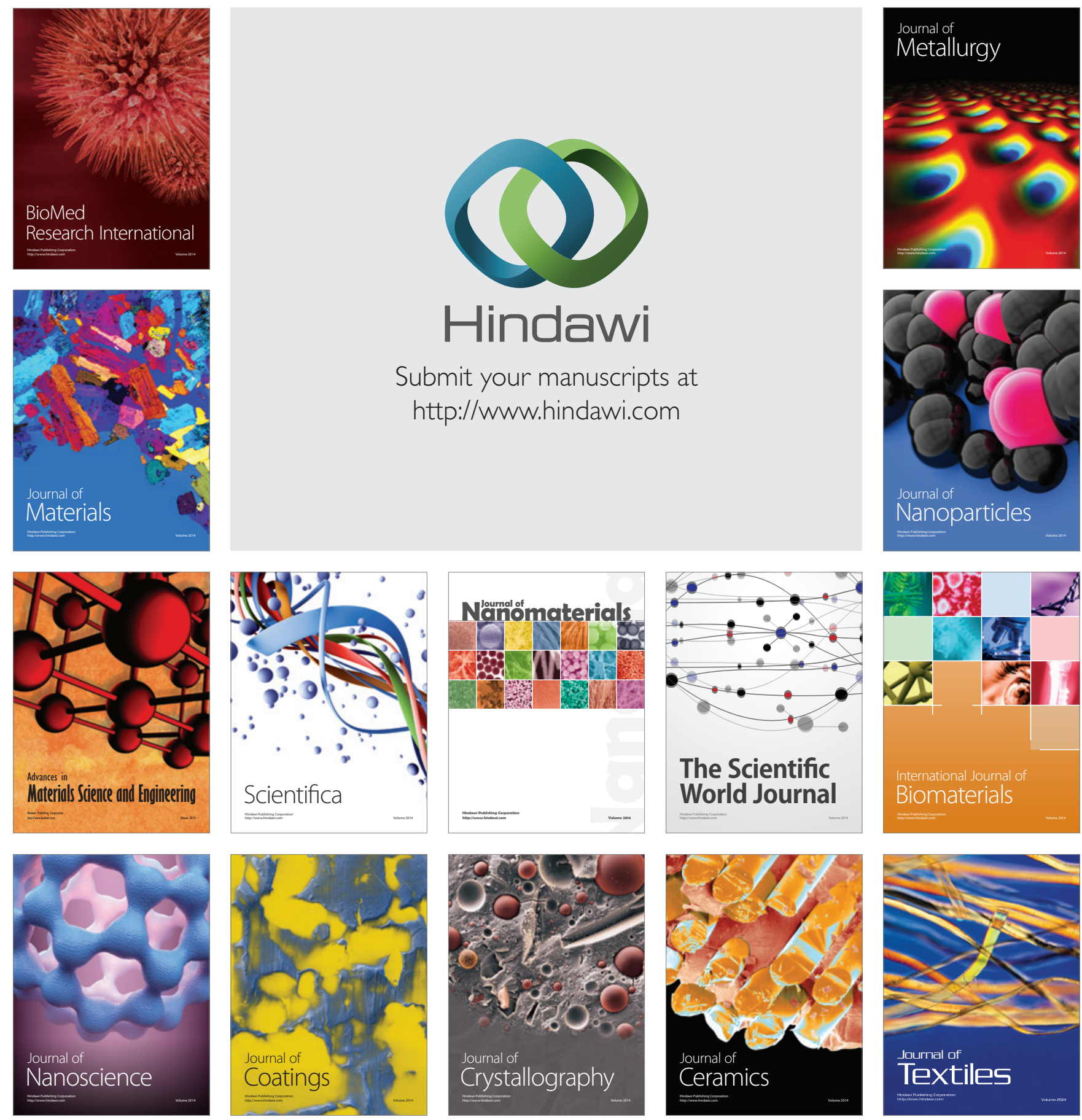